\title{
Effect of short- and long-term heat stress on the conception risk of dairy cows under natural service and artificial insemination breeding programs
}

\author{
L.-K. Schüller, O. Burfeind, and W. Heuwieser ${ }^{1}$ \\ Clinic for Animal Reproduction, Faculty of Veterinary Medicine, Freie Universität Berlin, Koenigsweg 65, 14163 Berlin, Germany
}

\begin{abstract}
The objectives of this retrospective study were to examine the effect of heat stress on natural service and artificial insemination (AI) breeding methods. We investigated the influence of short- and long-term heat stress on the conception risk (CR) of dairy cows bred by natural service or by AI with frozen-thawed or fresh semen. In addition, the relationship between breeding method and parity was determined. Cows bred by AI with frozen-thawed semen exposed to long-term heat stress (mean temperature-humidity index $\geq 73$ in the period $21 \mathrm{~d}$ before breeding) were $63 \%$ less likely to get pregnant compared with cows not exposed to heat stress. Cows bred by AI with fresh semen were $80 \%$ less likely to get pregnant during periods of short-term heat stress than during periods without heat stress. Furthermore, multiparous cows bred by AI with frozen-thawed or fresh semen were 22 and $67 \%$ less likely to get pregnant, respectively, than primiparous cows. No influence of heat stress or parity was noted on the CR of cows bred by natural service. The present study indicates that the likelihood of dairy cows becoming pregnant is reduced by short- and long-term heat stress depending on the type of semen employed. In particular, CR of cows inseminated with fresh semen is negatively affected by short-term heat stress and CR of cows inseminated with frozen-thawed semen is negatively affected by long-term heat stress.
\end{abstract}

Key words: heat stress, conception risk, artificial insemination, natural service, dairy cow

\section{INTRODUCTION}

Heat stress can have major effects on fertility and embryonic survival in lactating dairy cows (Hansen and Arechiga, 1999). These include disturbances in hormonal balance (Wilson et al., 1998; Roth et al., 2000),

Received July 7, 2015.

Accepted December 10, 2015

${ }^{1}$ Corresponding author: w.heuwieser@fu-berlin.de decreased follicle and oocyte quality (Wolfenson et al., 1995; Roth et al., 2000), and decreased embryo development and embryo survival (Wolfenson et al., 2000; De Rensis and Scaramuzzi, 2003). These processes lead to a decrease in conception rate during periods of heat stress ranging between 30 and $60 \%$ compared with periods without heat stress (De Rensis et al., 2002; Schüller et al., 2014). Even in temperate climates, conception rate of dairy cows decreases from $31 \%$ during cold climate conditions to less than $13 \%$ during periods of heat stress (Schüller et al., 2014).

Furthermore, reproductive performance of bulls is negatively affected by heat stress, resulting in reduced libido and sperm motility and an increased number of abnormal sperm (Nichi et al., 2006; Menegassi et al., 2015). Generally, ambient temperatures in the range of 5 to $15^{\circ} \mathrm{C}$ were found to be optimal for semen production (Parkinson, 1987; Fuerst-Waltl et al., 2006). In a study conducted in a temperate climate, a negative relationship between ambient temperature in periods of 11 and $65 \mathrm{~d}$ before sperm collection and percentage of viable spermatozoa and sperm motility was detected (Fuerst-Waltl et al., 2006).

Reduced reproductive performance of dairy cows in combination with reduced libido and semen quality of bulls during summer months can cause important economic losses to the dairy industry (Collier et al., 2006). Therefore, the breeding method used in periods of heat stress should be considered to maximize reproductive performance. As a result of impaired reproductive performance, AI has become popular, and AI upon natural estrus is still the most prevalent method to breed cows for first and subsequent services (Overton and Sischo, 2005; National Animal Health Monitoring System, 2009). In contrast to natural service, it is assumed that a decrease in semen quality due to heat stress can be avoided in AI breeding programs by the use of frozen semen (Hansen and Arechiga, 1999). Natural service bulls, however, have been considered as a profitable alternative for managing dairy herds when estrusdetection rates are abysmal during summer months (Jobst et al., 2000); therefore, natural service continues to be a popular component of the breeding system in 
many dairy herds (de Vries et al., 2005). Furthermore, in European dairy farms, it is common practice to breed repeat breeder cows and cows with reproductive issues by natural service. Few studies have compared reproductive performance between AI and natural service breeding systems during periods of heat stress, and none have done so in a temperate climate. Niles et al. (2002) found pregnancy rates of dairy cows bred by AI or natural service did not differ significantly during the hot season, although the level of heat stress was not assessed. In contrast, de Vries et al. (2005) reported lower pregnancy rates for AI-breeding herds than for natural service and combined breeding herds during periods of heat stress. In contrast, a dearth of information exists on the effect of different periods of heat stress on AI and natural service breeding programs. Finally, we found no documentation of the effect of heat stress on AI compared between frozen-thawed or fresh semen. Thus, the objective of our study was to determine the influence of short- and long-term exposure to heat stress on the conception risk (CR) of lactating dairy cows in different breeding programs. Furthermore, the relationship between breeding method and parity was determined.

\section{MATERIALS AND METHODS}

\section{Design of the Barn}

The retrospective study was conducted on a commercial dairy farm in Sachsen-Anhalt, Germany, from May 2010 to October 2012. The herd consisted of 1,150 Holstein dairy cows with an average milk production of $10,345 \mathrm{~kg}$ ( $4.0 \%$ fat, $3.3 \%$ protein). The barn was positioned in a northeast-southwest orientation $\left(51^{\circ} 77^{\prime} \mathrm{N}\right.$, $12^{\circ} 91^{\prime} \mathrm{E}$ ) with open ventilation and a mechanical fan system. Sixty fans were installed above the stalls and controlled manually by the farm manager. All cows were housed in a freestall facility with slatted floors and beds equipped with rubber mats. Group composition was dynamic, with cows entering and leaving the study barn depending on their calving dates. Cows were fed a TMR. The rations were formulated to meet or exceed the requirements of the NRC (2001). Lactating cows were milked 3 times a day at starting at 0600, 1400, and $2200 \mathrm{~h}$.

\section{Reproductive Management}

The voluntary waiting period was set at $55 \mathrm{~d}$ postpartum. Between 35 and $49 \mathrm{~d}$, cows received an initial injection of $25 \mathrm{mg}$ of $\mathrm{PGF}_{2 \alpha}$ (Dinoprost, Dinolytic, Zoetis Deutschland GmbH, Berlin, Germany) and a second injection of $25 \mathrm{mg}$ of $\mathrm{PGF}_{2 \alpha} 2$ wk later to regress the corpora lutea. Cows that showed estrus after the second injection of $\mathrm{PGF}_{2 \alpha}$ were $\mathrm{AI}$ or received natural service by a bull. Natural service was provided for all cows after caesarean section, with adhesions of the uterus and repeat breeder cows in third or higher lactation. Pedometers (Milkline, Gariga di Podenzano, Italy) and visual observation were used to detect estrus. Cows that did not show estrus after the second injection of $\mathrm{PGF}_{2 \alpha}$ within $3 \mathrm{~d}$ were excluded from the analysis. Inseminations were performed by 7 technicians within $12 \mathrm{~h}$ after detection of estrus with frozen-thawed or fresh semen from bulls $(\mathrm{n}=219)$ used randomly across inseminations depending on the availability of semen in fresh or frozen state. Pregnancy diagnoses were performed 35 to $42 \mathrm{~d}$ after the day of breeding with transrectal ultrasonography by the herd veterinarian. Cows with unclear pregnancy diagnosis were reexamined with transrectal ultrasonography 1 wk later. Cows that were diagnosed not pregnant were reassigned to breeding with natural service or AI with frozen-thawed or fresh extended semen depending on the results of the transrectal ultrasonography and the number of previous inseminations. Cows that were observed in estrus $>10 \mathrm{~d}$ after AI were assumed nonpregnant and reinseminated.

Frozen-thawed and fresh semen used for AI in this study was processed by the local AI center and sent daily to the dairy farm. Frozen semen was stored in 0.25 -mL straws within liquid nitrogen at $-196^{\circ} \mathrm{C}$. During the course of thawing, semen samples were taken out of the liquid nitrogen and thawed in a water bath at $37^{\circ} \mathrm{C}$ for $30 \mathrm{~s}$. Fresh semen was stored in thermoinsulated canisters at 10 to $15^{\circ} \mathrm{C}$ until insemination.

\section{Data Collection}

Ambient temperature and relative humidity within the experimental barn were recorded using a Tinytag Plus II logger (Gemini Loggers Ltd., Chichester, UK) secured at a beam $3 \mathrm{~m}$ from the ground within the barn. This logger measured ambient temperature from -25 to $85^{\circ} \mathrm{C}$, with an accuracy of $\pm 0.3^{\circ} \mathrm{C}$ and a resolution of $0.01^{\circ} \mathrm{C}$, and relative humidity from 0 to $100 \%$, with an accuracy of $\pm 3 \%$ and a resolution of $0.3 \%$. These data were recorded hourly. Ambient temperature (AT) and relative humidity $(\mathrm{RH})$ data were used to calculate the temperature-humidity index (THI) according to the equation reported by the NRC (1971): $\mathrm{THI}=(1.8 \times \mathrm{AT}+32)-[(0.55-0.0055 \times \mathrm{RH}) \times$ $(1.8 \times$ AT -26$)]$. Cow identification, parity, service dates, breeding method, number of services, and results of pregnancy diagnosis were obtained from computerized herd records managed using Herde (Version 5.5, Software Projektierungs- und Handels GmbH, Aschare, Germany). 


\section{Statistical Analyses}

Data from the onsite climate logger and from Herde were exported into Excel spreadsheets (Office 2013, Microsoft Deutschland GmbH, Munich, Germany) and statistical analysis was performed using SPSS for Windows (Version 19.0, SPSS Inc., IBM, Ehningen, Germany). Daily and monthly mean ambient temperature, relative humidity, and resulting THI were calculated from hourly measures. Short-term heat stress was defined as a mean THI $\geq 73$ at the day of breeding because heat stress around the day of breeding was consistently associated with reduced CR (García-Ispierto et al., 2007; Morton et al., 2007; Schüller et al., 2014). Long-term heat stress was defined as a mean THI $\geq 73$ in the period from d 21 to 1 before the day of breeding because heat stress beginning on $\mathrm{d} 1$ of the previous estrous cycle leads to a reduced number of follicles, a reduced concentration of estradiol in follicles, and to an earlier emergence of the dominant follicle (Wolfenson et al., 1995, 1997). In a study that compared the effect of heat stress on CR between 7 different periods around the day of breeding, heat stress at 3 wk before breeding had the greatest negative influence on CR (Schüller et al., 2014). In the current study, a THI $\geq 73$ on the day of breeding (short-term heat stress) or during the 21-d period before breeding (long-term heat stress) did not preclude presence of heat stress after breeding, in particular when heat stress is seasonal in contrast to sporadic heat stress episodes. Descriptive statistics of continuous variables were presented by median and range. For categorical data, frequencies of occurrence were presented. Conception risk was defined as the number of pregnant cows divided by the number of total services multiplied by 100 .

The association between heat stress (no heat stress, short-term heat stress, long-term heat stress), parity (primiparous vs. multiparous), number of services (1,2, $3, \geq 4$ services), and CR was determined in a multivariable logistic regression model for each breeding method (AI with frozen-thawed semen, AI with fresh semen, natural service). Furthermore, the interactions between heat stress and each variable were determined. The model was constructed in a backward stepwise manner with variables being continuously removed from the model by the Wald statistic criterion if the significance was greater than 0.20 . Odds ratios, including $95 \%$ confidence interval, were reported for all associations and significance was set at $P<0.05$. For all variables, one class of each variable was considered as the reference and an odds ratio significantly greater (or lower) than 1 for any other class of this variable was indicative of an increased (or reduced) risk for conception when compared with the class used as reference.

\section{RESULTS}

The data set contained 5,192 breeding records from 1,537 lactating dairy cows on a single dairy farm. The overall CR obtained was $33.0 \%$ and average days open were 129.3. Inseminations with frozen-thawed and fresh semen were conducted in 80.6 and $5.6 \%$ of the cows, respectively, and $13.8 \%$ of the cows were bred by natural service. The population of cows enrolled in the study consisted of $33.0 \%$ primiparous cows and $67.0 \%$ cows in the second or higher lactation. Frequency distribution of number of inseminations needed to establish a pregnancy was 32.8 ( 1 insemination), 28.0 (2 inseminations), 18.8 (3 inseminations), and $20.4 \%$ ( $\geq 4$ inseminations).

Minimum, maximum, and mean ambient temperature during the study period were $2.3,29.8$, and $16.0 \pm$ $5.5^{\circ} \mathrm{C}$, respectively. Minimum, maximum, and mean relative humidity during the study period were 48.9, 95.8, and $76.0 \pm 8.2 \%$, respectively. Minimum, maximum, and mean THI during the study period were $34.6,83.7$, and $60.4 \pm 8.5 \%$, respectively. Descriptive statistics for the mean THI per month are depicted in Figure 1.

In the multivariable logistic regression model investigating cows inseminated with frozen-thawed semen, the variables heat stress, parity and number of services remained significant (Table 1). No significant interactions were noted between heat stress and the variables parity and number of services. Multiparous cows bred by AI with frozen-thawed semen were $22 \%$ less likely to get pregnant than primiparous cows (Table 1). Cows bred by AI with frozen-thawed semen exposed to long-term

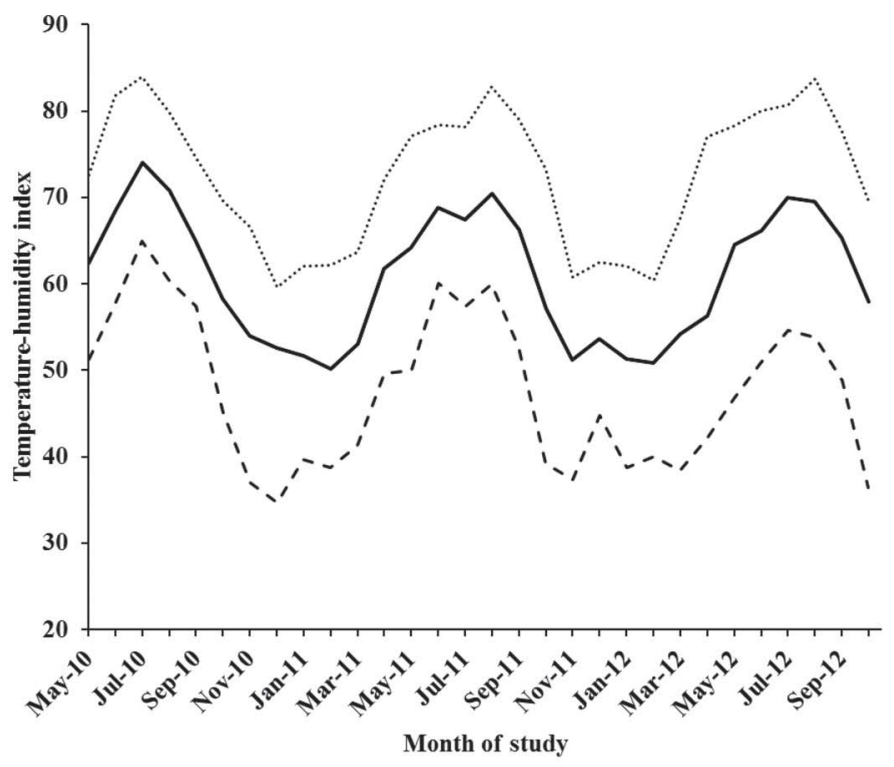

Figure 1. Mean (-), minimum (- - ), and maximum (...) temperature-humidity index in the barn from May 2010 to October 2012 (n $=913$ experimental days). 
Table 1. Results of multivariable logistic regression model and interactions of factors associated with conception risk in dairy cows inseminated with frozen-thawed semen

\begin{tabular}{lccrc}
\hline Variable & Odds ratio & $95 \% \mathrm{CI}$ & $\mathrm{n}$ & $P$-value \\
\hline Parity & Referent & & 4,184 & $<0.05$ \\
Primiparous & 0.78 & $0.68-0.90$ & 1,408 & 2,776 \\
Multiparous & & & 4,184 & $<0.05$ \\
Heat stress & Referent & & 3,928 & \\
No heat stress & 0.75 & $0.53-1.06$ & 174 & 0.10 \\
Short-term heat stress & 0.37 & $0.20-0.67$ & 82 & $<0.05$ \\
Long-term heat stress & & & 4,184 & $<0.05$ \\
Number of services & Referent & & 1,373 & \\
1 & 0.96 & $0.82-1.14$ & 1,173 & 0.67 \\
2 & 1.04 & $0.86-1.25$ & 785 & 0.71 \\
3 & 0.75 & $0.62-0.91$ & 853 & $<0.05$ \\
\hline 4 & & & & \\
\hline
\end{tabular}

heat stress were $63 \%$ less likely to get pregnant than cows not exposed to heat stress (Table 1). Cows bred by AI with frozen-thawed semen receiving $\geq 4$ services were $15 \%$ less likely to get pregnant than cows receiving 1 service (Table 1 ).

In the multivariable logistic regression model investigating cows inseminated with fresh semen, the variables heat stress and parity remained significant (Table 2 ). Number of services had no significant association with $\mathrm{CR}(P=0.28)$ and therefore was not included in the multivariable model. No significant interactions between heat stress and parity were observed. Multiparous cows bred by AI with fresh semen were $67 \%$ less likely to get pregnant than primiparous cows (Table 2). Cows bred by AI with fresh semen exposed to shortterm heat stress were $80 \%$ less likely to get pregnant than cows not exposed to heat stress (Table 2). In the multivariable logistic regression model investigating cows bred by natural service, the variables heat stress $(P=0.21)$, parity $(P=0.98)$, and number of services $(P=0.24)$ had no significant association to CR.

\section{DISCUSSION}

The present study demonstrates that both short- and long-term heat stress significantly reduce the likelihood of cows becoming pregnant bred by AI. Previous studies demonstrated that the $\mathrm{CR}$ of cows is negatively affected by extended heat stress, as well as on single days around the day of breeding (Morton et al., 2007; Schüller et al., 2014). In our study, however, the effect of short- and long-term heat stress differed depending on the breeding method. Long-term heat stress significantly reduced the likelihood of cows becoming pregnant when inseminated with frozen-thawed semen, whereas short-term heat stress significantly reduced the likelihood of cows becoming pregnant when inseminated with fresh semen. Furthermore, the effect of long-term heat stress on the likelihood of cows becoming pregnant when inseminated with fresh semen was barely statistically significant $(P=0.05$, Table 2$)$. These results are in agreement with previous studies demonstrating that long-term heat stress in the period before breeding significantly reduces $\mathrm{CR}$ of dairy cows (Wolfenson et al., 2000; Morton et al., 2007; Schüller et al., 2014).

Conception risk of cows inseminated with frozenthawed semen during periods of long-term heat stress decreased about 32.4 percentage points compared with periods without heat stress (Figure 1). Long-term heat stress before the day of breeding leads to a reduced number of follicles, a reduced concentration of estradiol in follicles and to an earlier emergence of the dominant follicle (Wolfenson et al., 1995, 1997). The advantage arising from the storage of semen in a frozen state is the possibility to maintain spermatozoa for a very long period. Hansen and Arechiga (1999) assumed that AI

Table 2. Results of multivariable logistic regression model and interactions of factors associated with conception risk in dairy cows inseminated with fresh semen

\begin{tabular}{lccrc}
\hline Variable & Odds ratio & $95 \% \mathrm{CI}$ & $\mathrm{n}$ & $P$-value \\
\hline Parity & & & 317 & $<0.05$ \\
Primiparous & Referent & & 42 & \\
Multiparous & 0.33 & $0.16-0.67$ & 275 & $<0.05$ \\
Heat stress & & & 317 & $<0.05$ \\
No heat stress & Referent & & 261 & \\
Short-term heat stress & 0.20 & $0.07-0.56$ & 30 & $<0.05$ \\
Long-term heat stress & 0.41 & $0.17-1.01$ & 26 & 0.05 \\
\hline
\end{tabular}


with frozen-thawed semen represented the best method for bypassing effects of heat stress on male fertility and the use of natural breeding squanders this benefit of AI. However, inadequate maintenance of storage temperatures in liquid nitrogen may occur during periods of high ambient temperature and can lead to far shorter time periods of survival of frozen semen (Vishwanath and Shannon, 2000). Furthermore, the effect of heat stress on the fertility and semen quality of AI bulls in the period before breeding may appear delayed due to the preservation of frozen storage of semen until the day of insemination.

Conception risk of cows inseminated with fresh semen during periods of short-term heat stress decreased by 25.4 percentage points (Figure 2) when compared with periods without heat stress. Fresh semen used for inseminations in our study was sent daily from the local AI station and stored in thermoinsulated canisters at 10 to $15^{\circ} \mathrm{C}$ until insemination. The optimum storage temperature of fresh semen ranges between 16 to $20^{\circ} \mathrm{C}$, and storage temperatures above this led to reduced semen fertility (Shannon and Curson, 1984; Vishwanath and Shannon, 2000). Long storage periods in combination with high ambient temperature can lead to an increase of the storage temperature and might explain poor CR during periods of short-term heat stress in our study. These findings support our hypothesis that climate conditions should be considered to optimize insemination programs and resulting CR on dairy farms. Particularly during periods of short-term heat stress, the on-site handling of fresh semen needs to be improved; however, temperatures for storage, freezing, and thawing processes were not recorded in our study. Further studies should investigate the effect of heat stress on fertility of bovine frozen and fresh semen under field conditions considering storage conditions and thawing procedures.

In contrast to cows bred by AI, cows bred by natural service were not affected by short- or long-term heat stress in the current study. Heat stress in bulls can lead to a reduced libido, sperm output, and motility and an increase in sperm abnormalities (Nichi et al., 2006; Menegassi et al., 2015). Although the natural service bulls in our study were housed in a freestall facility within the dairy farm, CR after natural service did not differ significantly between periods of heat stress and periods without heat stress. In a recent study, scrotal temperatures measured by infrared thermography were highly correlated with the daily THI (Menegassi et al., 2015), and increased testicular temperatures led to impaired spermatogenic cycle and impaired sperm quality (Nichi et al., 2006). In the current study heat stress just reached the maximum THI of 83 (Figure 1), and in the study of Menegassi et al. (2015) the aver- age THI of 83 did not cause significant morphological changes in sperm quality. However, a scarcity of studies exists investigating THI thresholds for the effect of heat stress on the libido and sperm quality of bulls in a temperate climate. Further research is necessary to investigate the effect of heat stress on the reproductive performance of bulls in the temperate climate. Some evidence exists that the use of natural service increases herd reproductive performance because bulls are supposed to be better at detecting estrus than humans because errors in estrus detection might be avoided (Vishwanath, 2003; Lima et al., 2009). During periods
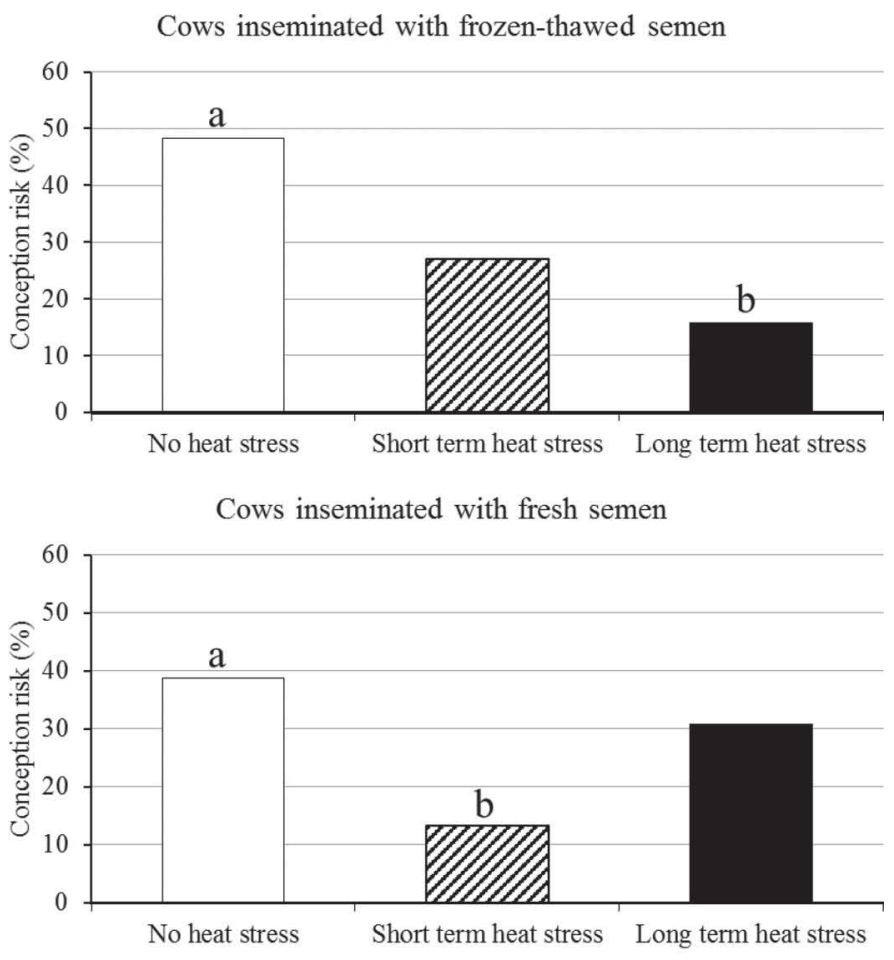

Cows bred by natural service

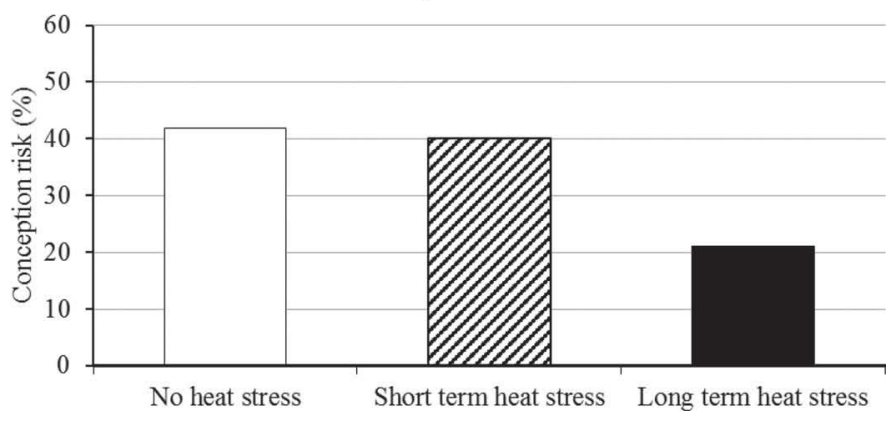

Figure 2. Conception risk of dairy cows bred by AI with frozenthawed $(\mathrm{n}=4,184)$ or fresh semen $(\mathrm{n}=317)$ or by natural service $(\mathrm{n}=716)$ during periods of short-term heat stress (striped bar) and long-term heat stress (black bar) compared with periods without heat stress (white bar). Bars with different letters (a,b) differ significantly $(P<0.05)$. 
of heat stress, estrus-detection rates can be reduced because mounting occurs more frequent during night and intensity of estrus is reduced (Orihuela, 2000). In the current study, a pedometer system in combination with visual observation was used to detect estrus in AI cows. Using an automated activity monitoring system for estrus detection in combination with visual observation led to estrus-detection rates of $56.3 \%$ in the first $21 \mathrm{~d}$ after the voluntary waiting period (Michaelis et al., 2014). Although manufacturers of automated activity monitoring systems claim high estrus-detection rates even under conditions that influence the cow movements because of individual threshold monitoring (Milkline, 2014), science-based information is not available. Further research is necessary to evaluate such estrus-detection systems under heat stress conditions, because the use of natural service bulls in dairy herds is a critical issue (Vishwanath, 2003; Lima et al., 2010). We emphasize that the benefit of natural service should be weighed against considerable risks associated with natural service, such as occupational safety, omission of gain in genetic merit, decreased predictability of time of birth, birth weight, and infertility in the dominant bull (Vishwanath, 2003; Lima et al., 2010).

In our study, the number of services is intrinsically related to CR of cows inseminated with frozen-thawed semen. These results corroborate earlier publications that report an inverse relationship for number of inseminations to CR (González-Recio et al., 2005; Weller et al., 2006). The number of inseminations to conception reflects the actual variation of female fertility and therefore is a direct measurement for the fertility in dairy cows (González-Recio et al., 2004). This negative relationship, however, was only observed for cows receiving $\geq 4$ inseminations with frozen-thawed semen and not observed in cows inseminated with fresh semen. These observations can be explained by lower case numbers for cows inseminated with fresh semen combined with a relatively small effect of number of inseminations on CR. Therefore, in the current study, this relationship was only apparent in cows receiving $\geq 4$ inseminations with frozen-thawed semen.

We observed that multiparous cows inseminated with frozen-thawed and fresh semen were 22 and $67 \%$ less likely to get pregnant, respectively, than primiparous cows (Tables 1 and 2). This observation agrees with previous studies that reported lower reproductive performance for multiparous cows (Chebel et al., 2004; Tenhagen et al., 2004; Astiz and Fargas, 2013). A possible reason for better fertility in primiparous cows is the lower milk production and the reduced risk of metabolic disorders in early lactation impairing reproductive efficiency (Tenhagen et al., 2004). In our study, no interaction was detected between heat stress and parity. Multiparous cows have higher milk production than primiparous cows (Hansen et al., 2006) and milk yield is closely related to increased DMI and increased metabolic heat production (Kadzere et al., 2002; Kononoff et al., 2006). This metabolic stress can lead to a decrease in CR during the hot season by 20 to $30 \%$ compared with the winter season (De Rensis et al., 2002). Therefore, multiparous cows can be affected by heat stress because an increase in milk yield is related to a decrease in heat tolerance (Berman et al., 1985; West, 2003). In our study, however, heat stress significantly decreased the likelihood of pregnancy in multiparous and primiparous cows. Our results are in line with a most recent study conducted in Spain including 7,805 cows demonstrated that $\mathrm{CR}$ was reduced during the hot season to a similar extend for primiparous and multiparous cows (Astiz and Fargas, 2013).

\section{CONCLUSIONS}

The present study indicates that the likelihood for dairy cows to become pregnant is reduced by short- and long-term heat stress depending on the form of semen used. Conception risk of cows inseminated with fresh semen was negatively affected by short-term heat stress, whereas CR of cows inseminated with frozen-thawed semen was negatively affected by long-term heat stress. Conception risk of naturally serviced cows was not affected by either duration of heat stress. Therefore, climate conditions on dairy farms should be considered when selecting breeding strategies to optimize AI and resulting CR, particularly during periods of short-term heat stress when fresh semen is used.

\section{ACKNOWLEDGMENTS}

We thank the collaborating dairy farm for providing us access to the reproductive performance data and for the possibility to collect the climate data. Laura-Kim Schüller was partly funded by the Dr. Dr. h. c. Karl Eibl-Foundation of the Neustadt a. d. Aisch A.I. Association (Neustadt a. d. Aisch, Germany) and Tiergyn Berlin e. V. (Berlin, Germany).

\section{REFERENCES}

Astiz, S., and O. Fargas. 2013. Pregnancy per AI differences between primiparous and multiparous high-yield dairy cows after using double Ovsynch or G6G synchronization protocols. Theriogenology 79:1065-1070.

Berman, A., Y. Folman, M. Kaim, M. Mamen, Z. Herz, D. Wolfenson, A. Arieli, and Y. Graber. 1985. Upper critical temperatures and forced ventilation effects for high-yielding dairy cows in a subtropical climate. J. Dairy Sci. 68:1488-1495.

Chebel, R. C., J. E. P. Santos, J. P. Reynolds, R. L. A. Cerri, S. O. Juchem, and M. Overton. 2004. Factors affecting conception rate 
after artificial insemination and pregnancy loss in lactating dairy cows. Anim. Reprod. Sci. 84:239-255.

Collier, R. J., G. E. Dahl, and M. J. VanBaale. 2006. Major advances associated with environmental effects on dairy cattle. J. Dairy Sci. 89:1244-1253.

De Rensis, F., P. Marconi, T. Capelli, F. Gatti, F. Facciolongo, S. Franzini, and R. J. Scaramuzzi. 2002. Fertility in postpartum dairy cows in winter or summer following estrus synchronization and fixed time AI after the induction of an $\mathrm{LH}$ surge with $\mathrm{GnRH}$ or hCG. Theriogenology 58:1675-1687.

De Rensis, F., and R. J. Scaramuzzi. 2003. Heat stress and seasonal effects on reproduction in the dairy cow-A review. Theriogenology 60:1139-1151.

de Vries, A., C. Steenholdt, and C. A. Risco. 2005. Pregnancy rates and milk production in natural service and artificially inseminated dairy herds in Florida and Georgia. J. Dairy Sci. 88:948-956.

Fuerst-Waltl, B., H. Schwarzenbacher, C. Perner, and J. Solkner. 2006. Effects of age and environmental factors on semen production and semen quality of Austrian Simmental bulls. Anim. Reprod. Sci. 95:27-37.

García-Ispierto, I., F. López-Gatius, G. Bech-Sabat, P. Santolaria, J. L. Yániz, C. Nogareda, F. De Rensis, and M. López-Béjar. 2007. Climate factors affecting conception rate of high producing dairy cows in northeastern Spain. Theriogenology 67:1379-1385.

González-Recio, O., Y. M. Chang, D. Gianola, and K. A. Weigel. 2005. Number of inseminations to conception in Holstein cows using censored records and time-dependent covariates. J. Dairy Sci. 88:3655-3662.

González-Recio, O., M. A. Pérez-Cabal, and R. Alenda. 2004. Economic value of female fertility and its relationship with profit in Spanish dairy cattle. J. Dairy Sci. 87:3053-3061.

Hansen, J. V., N. C. Friggens, and S. Højsgaard. 2006. The influence of breed and parity on milk yield, and milk yield acceleration curves. Livest. Sci. 104:53-62.

Hansen, P. J., and C. F. Arechiga. 1999. Strategies for managing reproduction in the heat-stressed dairy cow. J. Anim. Sci. 77(Suppl 2):36-50.

Jobst, S. M., R. L. Nebel, M. L. McGilliard, and K. D. Peizer. 2000. Evaluation of reproductive performance in lactating dairy cows with prostaglandin f2alpha, gonadotropin-releasing hormone, and timed artificial insemination. J. Dairy Sci. 83:2366-2372.

Kadzere, C. T., M. R. Murphy, N. Silanikove, and E. Maltz. 2002. Heat stress in lactating dairy cows: A review. Livest. Prod. Sci. 77:59-91

Kononoff, P. J., S. K. Ivan, W. Matzke, R. J. Grant, R. A. Stock, and T. J. Klopfenstein. 2006. Milk production of dairy cows fed wet corn gluten feed during the dry period and lactation. J. Dairy Sci. 89:2608-2617.

Lima, F. S., A. De Vries, C. A. Risco, J. E. P. Santos, and W. W. Thatcher. 2010. Economic comparison of natural service and timed artificial insemination breeding programs in dairy cattle. J. Dairy Sci. 93:4404-4413.

Lima, F. S., C. A. Risco, M. J. Thatcher, M. E. Benzaquen, L. F. Archbald, J. E. Santos, and W. W. Thatcher. 2009. Comparison of reproductive performance in lactating dairy cows bred by natural service or timed artificial insemination. J. Dairy Sci. 92:5456-5466.

Menegassi, S. R., J. Barcellos, E. Dias, C. Koetz Jr., G. Pereira, V Peripolli, C. McManus, M. Canozzi, and F. Lopes. 2015. Scrotal infrared digital thermography as a predictor of seasonal effects on sperm traits in Braford bulls. Int. J. Biometeorol. 59:357-364.

Michaelis, I., O. Burfeind, and W. Heuwieser. 2014. Evaluation of oestrous detection in dairy cattle comparing an automated activity monitoring system to visual observation. Reprod. Domest. Anim. 49:621-628.

Milkline. 2014. Heatime-the new automatic heat-detection system. Accessed Dec. 1, 2015. http://heatime.dk/Manual-eng.pdf.
Morton, J. M., W. P. Tranter, D. G. Mayer, and N. N. Jonsson. 2007. Effects of environmental heat on conception rates in lactating dairy cows: Critical periods of exposure. J. Dairy Sci. 90:2271-2278.

National Animal Health Monitoring System. 2009. Dairy 2007, Part IV: Reference of Dairy Cattle Health and Management Practices in the United States, 2007. USDA, Fort Collins, CO.

NRC. 1971. A Guide to Environmental Research on Animals. Natl. Acad. Sci., Washington, DC.

NRC. 2001. Nutrient Requirements of Dairy Cattle. 7th rev. ed. Natl. Acad. Sci., Washington, DC.

Nichi, M., P. E. J. Bols, R. M. Züge, V. H. Barnabe, I. G. F. Goovaerts, R. C. Barnabe, and C. N. M. Cortada. 2006. Seasonal variation in semen quality in Bos indicus and Bos taurus bulls raised under tropical conditions. Theriogenology 66:822-828.

Niles, D., C. A. Risco, and M. J. Thatcher. 2002. Seasonal evaluation of artificial insemination and natural service pregnancy rates in dairy herds. Compend. Contin. Educ. Pract. Vet. 24:44-48.

Orihuela, A. 2000. Some factors affecting the behavioural manifestation of oestrus in cattle: A review. Appl. Anim. Behav. Sci. 70:1-16.

Overton, M. W., and W. M. Sischo. 2005. Comparison of reproductive performance by artificial insemination versus natural service sires in California dairies. Theriogenology 64:603-613.

Parkinson, T. J. 1987. Seasonal variations in semen quality of bulls: Correlations with environmental temperature. Vet. Rec. 120:479 482.

Roth, Z., R. Meidan, R. Braw-Tal, and D. Wolfenson. 2000. Immediate and delayed effects of heat stress on follicular development and its association with plasma FSH and Inhibin concentration in cows. J. Reprod. Fertil. 120:83-90.

Schüller, L. K., O. Burfeind, and W. Heuwieser. 2014. Impact of heat stress on conception rate of dairy cows in the moderate climate considering different temperature-humidity index thresholds, periods relative to breeding, and heat load indices. Theriogenology 81:1050-1057.

Shannon, P., and B. Curson. 1984. Effect of storage temperature on the viability and fertility of bovine sperm diluted and stored in caprogen. N. Z. J. Agric. Res. 27:173-177.

Tenhagen, B.-A., R. Surholt, M. Wittke, C. Vogel, M. Drillich, and W. Heuwieser. 2004. Use of Ovsynch in dairy herds-Differences between primiparous and multiparous cows. Anim. Reprod. Sci. 81:1-11.

Vishwanath, R. 2003. Artificial insemination: The state of the art. Theriogenology 59:571-584.

Vishwanath, R., and P. Shannon. 2000. Storage of bovine semen in liquid and frozen state. Anim. Reprod. Sci. 62:23-53.

Weller, J. I., E. Ezra, and G. Leitner. 2006. Genetic analysis of persistency in the Israeli Holstein population by the multitrait animal model. J. Dairy Sci. 89:2738-2746.

West, J. W. 2003. Effects of heat-stress on production in dairy cattle. J. Dairy Sci. 86:2131-2144.

Wilson, S. J., R. S. Marion, J. N. Spain, D. E. Spiers, D. H. Keisler, and M. C. Lucy. 1998. Effects of controlled heat stress on ovarian function of dairy cattle. 1. Lactating cows. J. Dairy Sci. 81:21242131.

Wolfenson, D., B. J. Lew, W. W. Thatcher, Y. Graber, and R. Meidan. 1997. Seasonal and acute heat stress effects on steroid production by dominant follicles in cows. Anim. Reprod. Sci. 47:9-19.

Wolfenson, D., Z. Roth, and R. Meidan. 2000. Impaired reproduction in heat-stressed cattle: Basic and applied aspects. Anim. Reprod. Sci. 60-61:535-547.

Wolfenson, D., W. W. Thatcher, L. Badinga, J. D. Savio, R. Meidan, B. J. Lew, R. Braw-Tal, and A. Berman. 1995. Effect of heat stress on follicular development during the estrous cycle in lactating dairy cattle. Biol. Reprod. 52:1106-1113. 